\title{
Psychological Safety and Work Engagement of Senior High School Teachers: Moderating Role of Psychological Flexibility
}

\author{
Bakari Yusuf Dramanu, PhD \\ Eugene Yaw Milledzi, PhD \\ Lebbaeus Asamani, PhD \\ University of Cape Coast, Ghana
}

Doi:10.19044/ejes.v7no3a2 URL:http://dx.doi.org/10.19044/ejes.v7no3a2

\begin{abstract}
There is a dearth of research that investigated how and the mechanism through which psychology safety perceptions and work engagement are related among employees in the education setting, especially in Africa. The present paper investigated how senior high school teachers' perception of their psychological safety in their schools predicted their work engagement and the moderating role of psychological flexibility. The cross-sectional survey design was employed to collect data from a sample of 263 public senior high school teachers in the Tamale Metropolis in the Northern region of Ghana. Adapted standardised questionnaires were used to collect the data. Regression analysis, including the PROCESS procedure for testing of moderating effect, was the main analytical tool employed to test the hypotheses. Both psychological flexibility and perception of psychological safety were significant positive predictors of senior high school teachers' work engagement. Also, psychological flexibility significantly moderated the effect of psychological safety on work engagement. The study concluded that psychological safety is an important determinant of both the perception of psychological safety and work engagement. The paper therefore, recommends, among others, that management of educational institutions and other work settings provide interventions that would enhance psychological flexibility and the feeling of psychological safety among employees.
\end{abstract}

Keywords: Psychological flexibility of teachers, perception of psychological safety, teachers' work engagement, moderating effect of psychological flexibility. 


\section{Introduction}

The availability of work is a basic requirement that ensures the survival of individuals in society. There is a positive association between work and quality of lives of individuals because people who are engaged in meaningful economic activities can fulfil their personal needs such as food, clothing, shelter, health care as well as financial security (Wanless, 2016). This has paved the way for the establishment of numerous job opportunities in organisations all over the world and individuals who are memberships in these organisations spend time at the workplace order to earn a living (Leiter \& Bakker, 2010). It should be pointed out that while working in these organisations, the worker has to be committed, dedicated as well as emotionally stable to be productive at the workplace. It also implies that the worker should be fully engaged in the work he or she does (Gill, 2008).

Leiter and Bakker (2010) observed that work engagement can be attributed to a positive, fulfilling and affective-motivational state of workrelated wellbeing that contributes to the performance and job satisfaction of employees. This implies that employees who exhibit high levels of work engagement have high levels of energy and motivation, and they are enthusiastically involved in the work they do. The concept of work engagement denotes the ability of employees to bring their full potentials to solving organisational problems, connect with people and develop innovative ways of achieving set goals and objectives (Bakker \& Schaufeli, 2008).

To boost the work engagement of employees at the workplace, it is important to take into consideration the psychological safety perceptions and flexibility of employees. This is evident because of the need to maintain sufficient flexibility in the work environment to accommodate a variety of approaches to achieving organisational goals (Leiter \& Bakker, 2010). Work engagement is a critical work outcome because it has a lot of implications for employees' job performance. Hence, engaged employees find their work more enjoyable (Fredrickson, 2013). Schaufeli (2013) indicated that in ensuring employees' work engagement, their psychological safety and flexibility are crucial. Psychological safety and psychological flexibility of employees enable them to engage, connect, change and learn new ways of executing their tasks and contributing their quota to the development of the organisation.

In educational institutions, work engagement is not solely a concern for management. Every employee, therefore, shares responsibility to develop a vibrant and engaging work environment. In the school settings, for instance, it is important to create a room for workers' commitment, involvement, passion, enthusiasm, dedication and energy toward work (Schaufeli, 2013). 


\section{Psychological safety and work engagement}

Psychological safety is a key variable that drives the success of any organisation. According to Wanless (2016), psychological safety is used to describe a situation when employees have the feeling that taking an interpersonal risk will not result in embarrassment, shame or ridicule. Psychological safety, therefore, enables employees to engage, connect, change and learn new ways of executing their tasks and contributing their quota to the development of the organisation without any fear of being punished or victimised.

Psychological safety has been found to affect employees' work engagement. For example, Ariani (2015) in a study in Indonesia reported a strong positive association between psychological safety and employees' work engagement. Similarly, Nelson (2015) found that a psychologically safe environment improved employees' work engagement. The results of these studies point to the fact that in organisations where employees are psychologically safe, they become focused on accomplishing the goals despite the discomforts that inevitably come along with new experiences and ideas (Wanless, 2016).

It should be noted that in the school settings, employees' psychological safety is particularly relevant because it enables them to be dedicated and committed to influence the achievement of intended learning outcomes. May, Gilson and Harter (2004) reported that psychological safety mediated employees' job commitment and engagement. Psychological safety, therefore, brings a shared belief held by employees of a team that makes that team safe for interpersonal risk-taking. Similarly, Edmondson (1999) in a study concluded that psychological safety is associated with the learning behaviour of workers which consequently affects the job performance of employees. According to Stander and Rothmann (2010), interventions at the workplace that focus on the psychological safety and empowerment of employees would contribute to their work engagement, as the feeling of psychological safety allows employees to show much concern, vigour and dedication.

Organisational practitioners observed that when individuals do not feel psychologically safe, their willingness to engage in experiences that would facilitate their development and work engagement is hampered. The foregoing discussion suggests that psychological safety perception tends to influence the work engagement of employees. Given the relevance of psychological safety perception at the workplace, the present study investigated it a predictor of the work engagement of senior high school teachers. 


\section{Psychological flexibility and work engagement}

According to Onwezen, Van Veldhoven and Biron (2012), the functional processes of psychological flexibility are best grouped under acceptance and commitment, which are highly interactive and reinforce one another. Acceptance denotes the willingness to experience thoughts, feelings, and sensations without having to control or determine one's future (Bond \& Bunce, 2003). Commitment, on the other hand, refers to the process of persisting and changing behaviour towards values as well as goals; and remaining persisted in achieving those goals (Hayes et al., 2004). Psychological flexibility, therefore, encompasses an individual's ability to contact the present moment while embracing internal experiences without attempting to control them and depending upon what the situation affords, persist with or change one's behaviour in the pursuit of one's chosen goals or values.

Empirical studies suggest that psychological flexibility predicts employees' work engagement and performance. For example, Bond and Bunce (2000) reported that psychological flexibility was a strong predictor of the mental health of employees which consequently affected their work engagement. Baer (2003) also observed that psychologically flexible workers are less likely to exhaust resources such as energy and attention. They tend to have more resources available to effectively respond to changing job demands in their organisations (Hayes et al., 2004).

Psychological flexibility has been found to have a positive effect on work performance and commitment of employees as flexibility tends to facilitate goal-directed behaviour (Bond \& Hayes, 2002). Bond and Hayes indicated that highly flexible workers are more sensitive to performancerelated contingencies of reinforcement in their work environment which promote their engagement and job performance. This implies that highly flexible employees in any organisation at any given time are more likely to engage in goal-directed behaviour even when they are confronted with negative or difficult thoughts, emotions and sensations.

Ruiz (2017) in a study in Columbia on the predictive role of psychological flexibility in the development of job burnout reported that the relationship between exhaustion and cynicism was higher among participants with low levels of work-related psychological flexibility as compared to participants with high levels of psychological flexibility. Similarly, Bond, Lloyd, and Guenole (2013) reported that psychological flexibility was an individual characteristic that is an important determinant of mental health and behavioural effectiveness at the workplace.

Indeed, psychological flexibility, as a key psychological construct, tends to influence the relationships among other variables which include work engagement and even factors that ensure the safety of employees at the 
workplace. Ruiz (2017) observed among a sample of 209 Spanish workers that psychological flexibility accounted for additional variance in burnout symptoms. From the moderating effect analysis by Ruiz, it was concluded that the relationship between exhaustion and cynicism was higher among participants with low levels of work-related psychological flexibility as compared to participants with higher levels of psychological flexibility. Similarly, Boatemaa, Asante and Agyemang (2019) in a study with Ghanaian sample, found that psychological flexibility moderated the relationship between organisational commitment and corporate entrepreneurship among information technology workers. The findings point to the fact that psychologically flexible individuals are more likely to show withstand workplace challenges and exhibit a good work attitude.

Careful analysis of the relevant literature suggests that while studies on psychological safety and work engagement are common the corporate business and industrial settings, there is a dearth of such research among employees in the education setting. Also, psychological flexibility has been largely explored in clinical psychology research, with only a few cited in corporate and educational research. Furthermore, it has been observed that most of the studies involving these variables (e.g. Ariani, 2015; Stander \& Rothmann, 2010; Wanless, 2016) treated these variables in isolation without taking into consideration how they interact to influence employees' work engagement. Similarly, there are some inconsistencies in the findings of these studies which call for further work to be done to have a comprehensive appreciation of these phenomena at the workplace. It should be pointed out that looking at the necessity of employees' safety and flexibility in predicting their work engagement; it appears that very limited information can be found on the topic in the educational settings in the case of Ghana. It is against this background that the current study investigated the effects of psychological safety and psychological flexibility on work engagement among educational workers to fill this research gap.

\section{Hypotheses}

The following hypotheses were formulated based on the purpose and review of the pertinent literature:

$\mathrm{H}_{1}$ : Senior high school teachers' perceived psychological safety will predict their work engagement.

$\mathrm{H}_{2}$ : Senior high school teachers' level of psychological flexibility will predict their work engagement

$\mathrm{H}_{3}$ : Psychological flexibility and perceived psychological safety of senior high school teachers will be positively related.

$\mathrm{H}_{4}$ : Psychological flexibility will moderate the relationship between perceived psychological safety and work engagement of senior high school teachers. 


\section{Research Methods: \\ Research design}

The design employed for this study is the cross-sectional survey. The study obtained self-report data from a sample of senior high school teachers from the Tamale Metropolis in the Northern region of Ghana. The teachers reported their perceived psychological safety, work engagement and levels of psychological flexibility.

\section{Population}

There were seven public senior high schools in the Tamale Metropolis, and the total number of teachers in all the school was 561. This included 462 males and 98 females (Education Management Information System, EMIS, 2018).

\section{Sample and sampling procedure}

Given that the female teachers were relatively few, we targeted all of them, but 83 of them gave their consent for their study. The systematic random sampling procedure was used to proportionately sample 255 male teachers across the schools. However, only 248 consented to take part in the study. The total number of teachers that agreed to complete the questionnaire, therefore, was 331. Two hundred and seventy-five were returned (return rate of $83.01 \%$ ). Twelve of the cases were later excluded because some were not fully completed and other due to influential cases, leaving 263 for the final analysis. This is made up of 197 male teachers (74.9\%) and 66 female teachers $(25.1 \%)$. The average age of the teachers in the study was 39 years, and on the average, they had taught for 13 years at the time of the study. All the teachers had at least First (Bachelor's) degree, and most were married, with only a few being divorced/widowed (see Table 1).

Table 1: Demographic Characteristics of Respondents $(n=263)$

\begin{tabular}{lcll}
\hline Educational level & Percent & Marital Status & Percent \\
\hline First degree & 75 & Married & 75 \\
Master's degree & 24 & Never married & 22 \\
Others & 1 & Divorced/Widowed & 3 \\
\hline
\end{tabular}




\section{Research Instrument: \\ Work engagement scale}

The work engagement of teachers was measured with the threedimensional Utrecht Work Engagement Scale (UWES: Schaufeli \& Bakker, 2003). The UWES describes work engagement as constituting three aspects: vigour, dedication, and absorption. This measure is a 17-item scale which is rated on a 7-point Likert-type scale from 0 (never) to 6 (always).

Vigour is characterised by high levels of energy and mental resilience while working, the willingness to invest effort in one's work, and persistence even in the face of difficulties, and was measured with six items. A sample item is: "At my work, I feel bursting with energy".

The dedication dimension was assessed with five items that refer to deriving a sense of significance from one's work, feeling enthusiastic and proud about one's job, and feeling inspired and challenged by one's work. Sample items are: "I find the work that I do full of meaning and purpose", and "I am enthusiastic about my job".

The third dimension, absorption is a six-item measure that assesses the degree to which an individual is being totally and happily immersed in his/her work and finding it difficult to be detached from the work. Sample items are: "Time flies when I'm working"; and "I feel happy when I am working intensely." The reliability alpha coefficient for this sample was .72.

\section{Psychological safety scale}

Perceived psychological safety was measured with an adapted form of the six-item psychological safety scale by Edmondson and Wooley (2003). The scale is unidimensional and was rated on five-point Likert type of scale from 1 (strongly disagree) to 5 (strongly agree). Three items were reversedscored, and previous studies indicated good reliability coefficients for the scale. Reported reliability coefficients were above .80. For instance, Bresman and Zellmer-Bruhn (2013) reported alpha reliability coefficient of .87, and we obtained .89 in the present study. A sample item is: It is difficult to ask others in this school for help.

\section{Psychological flexibility scale}

The level of psychological flexibility of the teachers in the study was measured with the seven-item unidimensional scale by Bond, Lloyd and Guenole (2013). This scale measures psychological flexibility related to the work setting. The current paper used a 7-point scale, from 0 (never true) to 6 (always true). The possible score range on the scale in our study, therefore, ranged from 0 to 42 , with higher scores denoting more flexibility. Bond et al. reported a reliability alpha coefficient of .84 . Sample items are: "I can perform 
as required no matter how I feel", and "I can work effectively, even when I doubt myself."

\section{Pilot testing of research instruments}

Three standardized scales were adapted for the present study and were pilot tested with a sample of 43 teachers, comprising 27 males and 16 females in Upper West Region (a region next to the northern region where the study was conducted) to ensure that the wording of the items was appropriate for the school environment and the Ghanaian context.

Minor modifications were made to the original wordings of the items to reflect the school settings. For instance, the word "organisation" was replaced with "school" in some cases before the pilot testing was done. All the scales and their subscales showed good psychometric properties and were deemed appropriate and reliable for the current study. The Cronbach's alpha reliability was used for all scale and the coefficients obtained were: .87 for psychological flexibility, .86 for psychological safety, and .79 for the work engagement scale. All the scales were deemed acceptable for the present study as the coefficients were higher than the often-cited acceptable level of .70 (George \& James, 1993).

\section{Data collection procedure}

We sought written approval from the headmasters of the schools, and then distributed the questionnaires to teachers who had given their consent to take part in the study. The purpose of the study was explained to the teachers individually and they were assured of confidentiality of the data. Respondents were not required to write their names on the questionnaires, and there was no attempt to identify individual respondents. This means there was no threat to the safety of any respondent in the study. Teachers who were free at the time of the distribution completed their questionnaires and were taken immediately they had finished. It took between 25 to 35 minutes to complete a set of questionnaires.

\section{Results}

Table 2 presents the descriptive statistics of the three main variables, together with the three dimensions of work engagement. The skewness and kurtosis statistics were all below 1.0, indicating that there were no issues of serious concern with the data regarding the normality of the distribution. Table 3 also presents the possible score ranges of the three main variables, including the criteria for low, moderate and high levels of scores on the measures. The mean of $30.11(S D=6.81)$ for psychological flexibility falls within the high criterion of flexibility among the teachers. Thus, on average, the teachers reported a high level of psychological flexibility. The results also suggest that 
the teachers perceived moderately psychologically safe $(M=19.84, S D=$ 4.96), and demonstrated a high level of work engagement $(M=73.83, S D=$ 15.66).

Table 2: Descriptive statistics of the two main variables and the dimensions of work engagement

Mean Std. Skewness Kurtosis

Deviation

\begin{tabular}{lllllll}
\hline Vigour & 26.23 & 5.54 & -.434 & .150 & -.200 & .299 \\
Dedication & 22.75 & 5.33 & -.684 & .150 & .262 & .299 \\
Absorption & 24.85 & 6.27 & -.139 & .150 & -.957 & .299 \\
Flexibility & 30.11 & 6.81 & -.289 & .150 & -.903 & .299 \\
Psyc. Safety & 19.84 & 4.96 & -.091 & .150 & -.728 & .299 \\
Work Engagement & 73.83 & 15.66 & -.329 & .150 & -.589 & .299
\end{tabular}

The possible score ranges and low, moderate and high criteria for the main variables are presented in Table 3 . For instance, for psychological flexibility, the possible scores range from zero $(0 \times 7)$ to $42(6 \times 7)$. This is because the scale consists of 7 items and rated on a seven-point Likert type scale, from never (0) to always (6).

Table 3: Possible score ranges and criteria for low, moderate and high levels of the measures

\begin{tabular}{lllll}
\hline Variable & Score range & Low & Moderate & High \\
\hline Flexibility & $0-42$ & $0-14$ & $15-28$ & $29-42$ \\
Psyc safety & $0-36$ & $0-12$ & $13-24$ & $25-36$ \\
Work & $0-102$ & $0-34$ & $35-68$ & $69-102$ \\
engagement & & & & \\
\hline
\end{tabular}

The results (see Table 4) further indicated that most of the teachers scored moderate to high on the psychological flexibility measure, with the majority exhibiting high flexibility. Concerning psychological safety, most of the teachers reported a moderate level of perceived safety, while the majority reported a high level of work engagement. 
Table 4: Frequencies and percentages of teachers who fall within low, moderate and high categories on the main variables measured

\begin{tabular}{llll}
\hline Variable & Low & Moderate & High \\
\hline Flexibility & $2(.8 \%)$ & $103(39.2 \%)$ & $158(60.15 \%)$ \\
Psyc safety & $20(7.6 \%)$ & $204(77.6 \%)$ & $39(14.8 \%)$ \\
Work engagement & $2(.8 \%)$ & $97(36.9 \%)$ & $146(62.4 \%)$ \\
\hline
\end{tabular}

$H_{1}$ : Senior high school teachers' perceived psychological safety will predict their work engagement.

$\mathrm{H}_{2}$ : Senior high school teachers' level of psychological flexibility will predict their work engagement.

The standard linear multiple regression analysis was used to test hypotheses 1 and 2. Preliminary analysis of the data indicated that there were no violations of the assumptions of normality, linearity and multicollinearity. The results presented in Table 5 showed that the model was significant $\left(\mathrm{R}^{2}=\right.$ $\left..142, \mathrm{~F}_{(2,260)}=21.73, \mathrm{p}<.001\right)$. Both psychological flexibility $(\beta=.298, \mathrm{p}<$ $.001)$ and psychological safety $(\beta=.141, \mathrm{p}=.026)$ significantly predicted work engagement of the senior high school teachers. Psychological flexibility was a stronger predictor of work engagement than psychological safety, with both relating positively with work engagement.

Table 5: Results of work engagement regressed on psychological flexibility (flex) and psychological safety (PSafety)

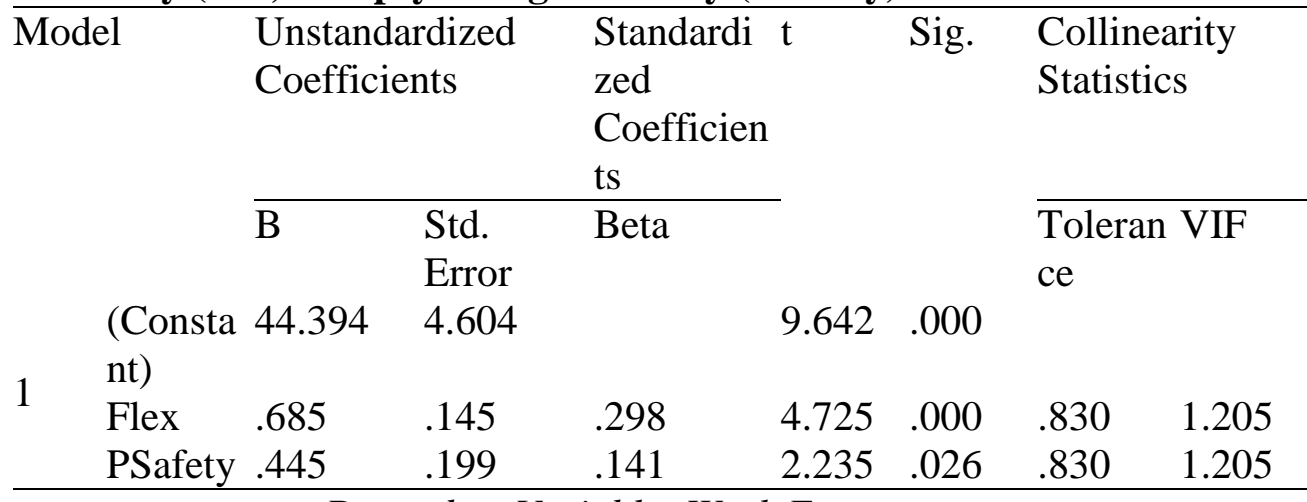

Dependent Variable: Work Engagement

H3: Psychological flexibility and perceived psychological safety of senior high school teachers will be positively related.

Pearson's Product Moment correlation was used to test hypothesis 3. The results showed a significant moderate positive relationship between psychological safety and psychological flexibility $\left(\mathrm{r}=.413, \mathrm{r}^{2}=.170, \mathrm{p}<\right.$ $.001)$. Thus, the two variables shared variance of $17.0 \%$. This result indicates 
that psychologically flexible teachers were more likely to feel psychologically safe in their schools.

H4: Psychological flexibility will moderate the relationship between perceived psychological safety and work engagement of senior high school teachers.

The PROCESS procedure (Hayes, 2018) was used to test the moderating effect of psychological flexibility on the effect of psychological safety on work engagement of the teachers. Psychological safety was categorised into low, moderate and high, while psychological flexibility was categorised into low and high (given that only 2 respondents fell into the low category when the low, moderate and high criteria were used for psychological flexibility). Table 6 presents the estimated conditional means of work engagement. This shows teachers' work engagement mean scores at different levels of psychological safety and psychological flexibility.

Table 6: Estimated conditional work engagement means being compared at different levels of psychological safety and psychological flexibility

\begin{tabular}{lll}
\hline Variables & \multicolumn{2}{l}{ Mean work engagement scores at: } \\
\cline { 2 - 3 } Psyc safety levels & Low Psyc flex & High Psyc flex \\
\hline Low & 80.44 & 66.36 \\
Moderate & 65.72 & 77.69 \\
High & 80.14 & 81.88 \\
\hline
\end{tabular}

At the low level of psychological flexibility, low perception of psychological safety had a mean work engagement of 80.44; work engagement mean of 65.72 for the moderate level of psychological safety and 80.14 for a high level of psychological safety. There seemed to be a curvelinear relationship between psychological safety and work engagement at the low level of psychological flexibility. At the high level of psychological flexibility, work engagement scores increased as psychological safety perception increased.

Figure 1 presents the interaction plot for visualizing the conditional effect of psychological safety at low and high levels of psychological safety. 


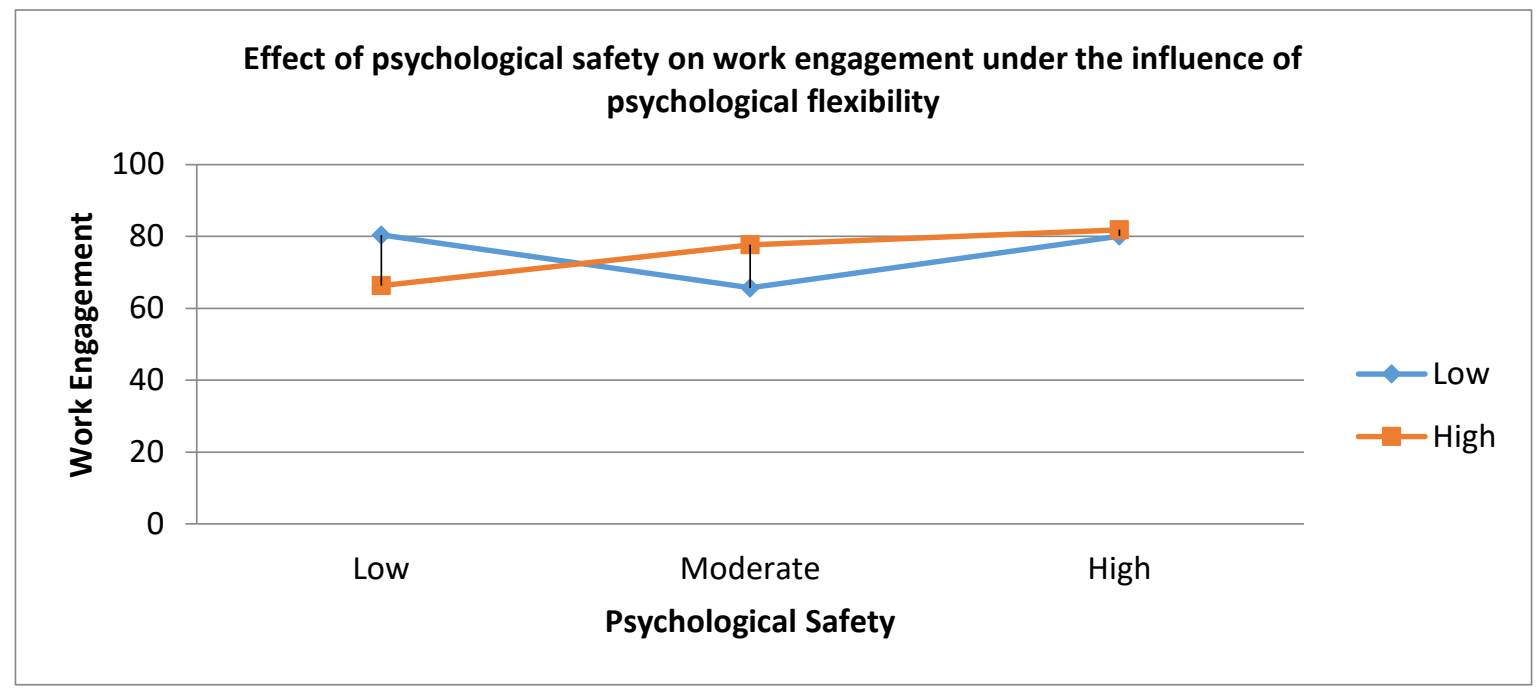

Figure 1: Interaction plot depicting the mean work engagement at different levels of psychological safety and psychological flexibility

The results show that teachers who reported moderate psychological safety exhibited significantly lower work engagement than those who reported low levels of psychological safety $(\beta=-14.73, \mathrm{p}=.004$; CI: $-24.65,-4.81)$. Those who reported high psychological safety, however, did not significantly differ from those who reported low levels of safety $(\beta=-.302, p=.967$; CI: $14.59,13.99)$.

The psychological flexibility and work engagement analysis also depict that teachers who reported high levels of psychological flexibility exhibited significantly lower work engagement than those who reported low levels of psychological flexibility $(\beta=-14.08, p=.031$; CI: $-26.83,-1.34)$.

The regression model summary indicated that the model was significant $\left(\mathrm{R}=.412, \mathrm{R}^{2}=.170, \mathrm{p}<.001\right)$. Thus, the psychological safety and psychological flexibility were significant predictors of work engagement of senior high school teachers in our sample, accounting for a variance of $17.0 \%$. Table 7 presents the regression coefficients for the direct and interaction effects in the model. 
Table 7: Results of direct and interaction effect analysis of psychological safety and psychological flexibility on work engagement

\begin{tabular}{|c|c|c|c|c|c|c|}
\hline Variable & Coefficient & SE & $\mathbf{t}$ & $\mathbf{P}$ & LLCI & ULCI \\
\hline Constant & 80.44 & 4.80 & 16.76 & .000 & 70.99 & 89.90 \\
\hline X1 & -14.73 & 5.04 & -2.92 & .004 & -24.65 & -4.81 \\
\hline $\mathrm{X} 2$ & -.302 & 7.26 & -.042 & .967 & -14.59 & 13.99 \\
\hline W1 & -14.08 & 6.47 & -2.18 & .031 & -26.83 & -1.34 \\
\hline Int_1 & 26.05 & 6.78 & 3.84 & .000 & 12.69 & 39.41 \\
\hline \multirow[t]{3}{*}{ Int_2 } & 15.81 & 8.83 & 1.79 & .075 & -1.58 & 33.21 \\
\hline & & & $X 1$ & $W 1$ & & \\
\hline & & & $X 2$ & $W 1$ & & \\
\hline
\end{tabular}

The interaction effect (Int_1) at the moderate level of psychological safety was statistically significant $(\beta=26.05, p<.001 ; C I$ : $12.69,39.41)$, while that at the high level was not significant $(\beta=15.81, \mathrm{p}=.075$; CI: -1.58 , 33.21). The unconditional (overall: $\mathrm{X} * \mathrm{~W}$ ) interaction showed a significant effect $\left(\mathrm{R}^{2}\right.$-change $\left.=.053, \mathrm{~F}_{(2,257)}=8.15, \mathrm{p}<.001\right)$. This indicates that, overall, there was a significant moderating effect of psychological flexibility on the relationship between psychological safety and work engagement.

Further analysis of the conditional effects of the focal predictor (psychological safety) at specific values of the moderator (psychological flexibility) was done. The results indicated that, at the low level of psychological flexibility, the effect of psychological safety on work engagement was significant and positive, $F_{(2,257)}=4.75, \mathrm{p}=.009$. The test of equality of conditional means indicated that, at the low level of psychological flexibility, the mean work engagement difference between teachers who had moderate and low perceptions of psychological safety $(B=11.32, \mathrm{p}=.013$, CI: $2.37,20.27)$, and between those who perceived high and low $(B=15.51$, $\mathrm{p}=.002$, CI: 5.60, 25.42) were significant.

Also, at the high level of psychological flexibility, there was a significant positive effect of psychological safety on work engagement, $F_{(2}$, 257) $=6.53, \mathrm{p}=.002$. The difference in work engagement between teachers who perceived moderate psychological safety and low $(B=37.37, \mathrm{p}<.001$, CI: 16.91, 57.84), and between high and low $(B=31, \mathrm{p}=.012$, CI: 6.89 , 55.76). 


\section{Discussion}

The results of the study show that both psychological safety and psychological flexibility significantly predicted work engagement of senior high school teachers in the Tamale Metropolis. This finding is well-grounded in the literature. For example, researchers such as (Leiter \& Bakker, 2010; Schaufeli, 2013) underscored the significance of psychological safety and psychological flexibility in predicting work engagement of employees. The findings of our study point to the fact that psychological safety and psychological flexibility as significant predictors of work engagement of teachers in the Tamale Metropolis enables them to connect change and also learn new ways of executing their tasks as educators.

Fredrickson (2013) argues that in instances where employees feel psychologically safe and flexible, they tend to exhibit a high sense of commitment and dedication at the workplace. Our findings further give prominence to the view that in educational institutions, both psychological safety and psychological flexibility of teachers are functional pre-conditions for ensuring effective teaching and learning. This is because teachers who are psychologically safe and flexible are more likely to use their abilities to make informed choices that would eventually positively influence the learning outcomes of their students.

Further, our findings show that psychological flexibility was a stronger predictor of work engagement than psychological safety, with both relating positively with work engagement. This aligns with earlier studies by (Bond \& Bunce, 2000; Edmondson, 1999; Stander \& Rothman, 2010). These researchers concluded that there existed a nexus between both psychological safety and psychological flexibility, and work engagement. Specifically, Bond and Bunce (2000) reported that psychological flexibility is a strong predictor of the mental health of employees which eventually affects their work engagement. Similarly, Edmondson (1999) concluded that psychological safety is positively associated with the learning behaviour of workers which influences their work engagement. Stander and Rothman (2010) argued that psychological safety and psychological flexibility contribute significantly to employees' work engagement. The results of the present study give the impression that when teachers are psychologically flexible, they tend to easily adapt to changing circumstances within their psycho-social work environment.

The results again showed that psychological flexibility significantly moderated the effect of psychological safety on work engagement of teachers in the Tamale Metropolis. The implication of this finding reinforces the concerns of psychological flexibility in organisational behaviour. Specifically, the finding of our study is consistent with a growing body of evidence that demonstrates the ability of psychological flexibility interacting with 
psychological safety to influence work engagement of employees (Onwezen, Veldhoven \& Biron, 2012; Ruiz, 2017). This implies that if teachers with greater psychological flexibility are given more job control in the school settings, they are more likely to identify opportunities to pursue goal-oriented actions which presumably involve making their work rewarding. This is in line with the works of Bond and Bunce (2003) who in their longitudinal study reported that employees with higher psychological flexibility benefited from higher levels of job control which also corroborates the assertion of Onwezen et al. (2012) that workers with greater psychological flexibility possess higher goal-oriented and context-sensitivity with an increased capacity to learn new skills at the workplace.

Finally, in contextualising the moderating effect of psychological flexibility on psychological safety and work engagement of senior high school teachers in this paper, it is important to state that teachers as agents of socialisation in the schools in particular and the society as a whole deal with students from diverse socio-cultural backgrounds. As Egan (2012) noted, the crux of every educational system is the quest for teachers to initiate young people into the knowledge, skills, values and attitudes that are common to the older generation of society. Therefore, teachers as agents of socialisation need to be psychologically safe and flexible in the school settings to ensure that young people effectively learn and gain the requisite knowledge, skills, values and attitudes that defined and sustained the lives in a particular society at any given time. The results of this study further point to the fact that psychological flexible teachers are more likely to be sensitive to performance-related contingencies in their schools. This, therefore, promotes their job performance and work engagement (Maccy \& Schnerder, 2008).

\section{Conclusion and Recommendations:}

The results of the current study provide evidence to conclude that psychological flexibility plays a key role in employees' perception of psychological safety, as well as work engagement. More importantly, psychological flexibility is a key determinant in the perception of psychological safety at the workplace. Also, our study provides considerable evidence to support the idea that a climate of psychological safety and psychological flexibility can mitigate the interpersonal risks inherent in learning hierarchies of employees in organisations, particularly among senior high school teachers. In line with the findings of this study, it can be concluded that, with the increasing numbers of collaborative relationships and complex interdependencies in the workplace, especially in second cycle educational institutions, psychological safety and psychological flexibility are likely to remain significant factors for predicting work engagement of employees. 
Based on the findings, the following recommendations are worthy of note in ensuring an improved psychosocial work environment in senior high schools. Firstly, Bond et al. (2013) indicated that even though psychological flexibility is usually considered an individual characteristic because it tends to be stable over time, effective interventions can also enhance it among individual. Given that our findings indicated the crucial role psychological flexibility plays in the perception of safety at work and work engagement, we recommend that the Ghana Education Service specifically, and other corporate organisations take steps to provide interventions for employees to boost their flexibility. Being psychologically flexible has enormous benefits for mental health and behavioural effectiveness in various settings, including the workplace (Bond et al., 2013).

Also, given that employees who perceived the workplace to be psychologically safe are more likely to put in more efforts and be immersed in their work, we recommend that educational institutions and other work settings should ensure transparency, fairness in the application of corporate rules and put measures in place to enhance interpersonal trust and solidarity among workers. Management must show genuine concern and care for the social and psychological wellbeing of their workers. When these recommendations are implemented, the institution would be the ultimate beneficiary, and the benefit would trickle down to the employees, in terms of their social, economic and psychological well-being and enhanced work experience.

\section{Limitations of the Study}

The study was conducted among senior high school teachers. For this reason, the findings must be applied to workers at other levels of education, as well as other work settings with caution. We, therefore, recommend further studies of this nature at other levels of education and other work settings to get a comprehensive picture of the issue under discussion. 


\section{References:}

1. Ariani, D. W. (2015). Relationship with supervisor and co-workers, psychological condition and employee engagement in the workplace. Journal of Business and Management, 4(3), 34-47.

2. Baer, R. A. (2003). Mindfulness training as a clinical intervention: A conceptual; and empirical review. Clinical Psychology, Science and Practice, 10,125-143.

3. Bakker, A. B. \& Schaufeli, W. B. (2008). Positive organisational behaviour: Engaged employees in flourishing organisations. Journal of Organizational Behaviour, 29(2), 147-154.

4. Boatemaa, M, A., Asante, O. K., \& Agyemang, C. B. (2019). The moderating role of psychological flexibility in the relationship between organizational commitment, work holism, job security, and corporate entrepreneurship among information technology workers in Accra, Ghana. Sage Open Journal, 1-9.

5. Bond, F. W. \& Bunce, D. (2000). Outcomes and mediators of change in emotion-focused and problem-focused worksite stress management interventions. Journal of Occupational Health Psychology, 5(1), 156 $-163$.

6. Bond, F. W., \& Bunce, D. (2003). The role of acceptance and job control in mental health, job satisfaction, and work performance. Journal of Applied Psychology, 88, 1057-1067.

7. Bond, F. W.\& Hayes, S. C. (2002). ACT at work. Chapter in F. Bond \& W. Dryden (Eds.), Handbook of brief cognitive behaviour therapy, Wiley, Chichester, England, pp. 117-140.

8. Bond, F. W., Lloyd, J., \& Guenole, N. (2013). The work-related acceptance and action questionnaire (WAAQ): initial psychometric findings and their implications for measuring psychological flexibility in specific contexts. Journal of Occupational and Organisational Psychology, 86, 331-347.

9. Bond, F. W., Hayes, S. C., Baer, R. A., Carpenter, K. M., Guenole, N., Orcutt, H. K., et al. (2011). Preliminary psychometric properties of the acceptance and action questionnaire - II: a revised measure of psychological flexibility and experiential avoidance. Behavioural Therapy.42, 676-688. doi: 10.1016/j.beth.2011.03.007

10. Bresman, H. \& Zellmer-Bruhn, M. (2013). The structural context of team learning: effects of organisational and team structure on internal and external learning. Organisation Science, 24(4), 1120-1139.

11. De Cooman, R., De Gieter, S., Pepermans, R., Jegers, M., \& Van Acker, F. (2009). Development and validation of the work effort scale. European Journal of Psychological Assessment, 25(4), 266-274. 
12. Edmondson, A. (1999). Psychological safety and learning behaviour in work teams. Administrative Science Quarterly, 44, 350-383.

13. Edmondson, A.C. \& Woolley, A. W. (2003). Understanding outcomes of organizational learning interventions, In M. Easterby-Smith \& M. Lyles (Eds), International Handbook on Organizational Learning and Knowledge Management, Blackwell, London.

14. Egan, L. (2012). Competing voices for the curriculum. In Gibson, S.(Ed,), Canadian curriculum studies, trends, issues and influences, Pacific Educational Press, Vancouver, pp. 45-62.

15. Fredrickson, B. I. (2013). Positive emotion broadens and build. Advances in Experimental Social Psychology, 47, 1-53.

16. George J, \& James, L. (1993). Personality, affect and behaviour in groups revisited: comment on aggregation, levels of analysis, and a recent application of within and between analysis. Journal of Applied Psychology, 78, 789-804.

17. Gill, R. (2008). Empowerment/sexism: figuring female sexual agency in contemporary advertising. Sage Journal, 18(1), 35-60.

18. Hayes, A. F. (2018). Partial, conditional, and moderated mediation: quantification, inference, and interpretation. Communication Monographs, 85, 4-40.

19. Hayes, S. C., Bissett, R., Roget, N., Padilla, M., Kohlenberg, B. S., Fisher, G., Masuda, A., Pistorello, J., Rye, A. K., Berry, K., \& Niccolls, R. (2004). The impact of Acceptance and Commitment Training on stigmatising attitudes and professional burnout of substance abuse counsellors. Behaviour Therapy, 35, 821-836.

20. Kacmar, K. M., \& Ferris, G. R. (1991). Perceptions of organizational politics scale (POPS): development and construct validation. Educational and Psychological Measurement, 51(1), 193-205.

21. Kahn, W. A. (1990). Psychological conditions of personal engagement and disengagement at work. Academy of Management Journal, 33, 692-724.

22. Leiter, M., \& Bakker, A. (2010). Work engagement: Introduction. Retrieved from: https://www.researchgate.net/publication/279545368. Retrieved on (January 2019)

23. Maccy, W. H., \& Schneider, B. (2008). The meaning of employee engagement. Industrial and Organisational Psychology, 1, 3-30.

24. May, R. D., Gilson, L. G., \& Harter, M. L. (2004). The psychological conditions of meaningfulness, safety and availability and the engagement of the human spirit at work. Journal of Occupational and Organisational Psychology, 77, 11- 37.

25. Nelson, S. F. (2015). Say, Stay or Strive: the effects of leadership style and psychological safety on employee engagement. Unpublished 
undergraduate dissertation, Dublin Business School, School of Arts, Dublin.

26. Onwezen, M. C., Van Veldhoven, M., \& Biron, M. (2012). The role of psychological flexibility in the demand-exhaustion performance relationship. European Journal of Work and Organisational Psychology, 23(2), 163-176.

27. Ruiz, F. J. (2017). The predictive and moderating role of psychological flexibility in the development of job burnout. University Psychologica, 16(4), 1-8.

28. Schaufeli, W. (2013). Work Engagement: What do we know? Utrecht: International OHP workshop, Timisoara.

29. Schaufeli, W. B., Bakker, A. B., \& Salanova, M. (2006). The measurement of work engagement with a short questionnaire: a crossnational study. Educational and Psychological Measurement, 66(4), 701-716.

30. Stander, M. W., \& Rothmann, S. (2010). Psychological empowerment, job insecurity and employee engagement. Journal of Industrial Psychology, 36(1), 849-857.

31. Wanless, B. S. (2016). The role of psychological safety in human development. Research in Human Development, 13(1), 1-12 